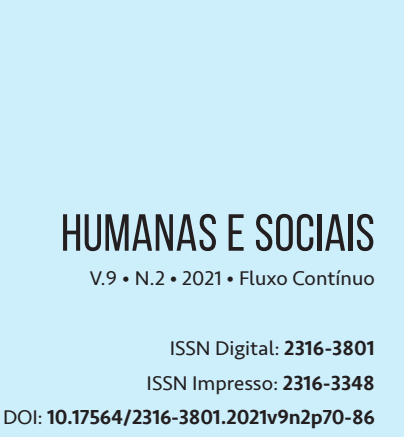

\section{LAZER DE CRIANCCAS BRASILEIRAS: ANÁLISE SOBRE O DIREITO AO LAZER}

LEISURE OF BRAZILIAN CHILDREN:

ANALYSIS ON THE HUMAN RIGHT TO LEISURE

OCIO DE LOS NIÑOS BRASILEÑOS:

ANÁLISIS SOBRE EL DERECHO HUMANO AL OCIO
Sheylazarth Ribeiro ${ }^{1}$ Aládia Medina ${ }^{2}$

Luciano Silveira Coelho 3 Hélder Ferreira Isayama ${ }^{4}$ Edmur Antonio Stoppa ${ }^{5}$

\section{RESUMO}

Neste artigo apresentamos análises do que crianças fazem como lazer, o que gostariam de fazer e não fazem como lazer, o que fazem como obrigação, bem como obstáculos para vivências do lazer. O estudo tem nível de confiança de 95\%, com amostragem total de 2400 entrevistas, sendo 211 com crianças (7-10 anos) das cinco regiões brasileiras realizadas pela técnica de survey. No Brasil, o lazer se apresenta como direito social para as crianças, fortalecendo a perspectiva internacional dos Direitos Humanos. As crianças brasileiras como obrigação apresentam a escola como resposta mais frequente, seguida pelos afazeres domésticos. Quanto ao que fazem como lazer, os interesses físico-esportivos são atividades frequentes no fim de semana, e, durante a semana, apresentamos a necessidade de mais dados sobre infância e mídias de internet. Quanto às barreiras para viver o lazer, a falta de recurso financeiro e de tempo foram apontados como os grandes empecilhos.

\section{PALAVRAS-CHAVE}

Crianças. Atividades de Lazer. Direitos Humanos. 


\section{ABSTRACT}

In this article, we analyses of what children do as leisure, what they would like to do but do not do as leisure, what they do as an obligation, as well as obstacles to leisure experiences. The study has a confidence level of $95 \%$, with a total sampling of 2400 interviews, being 211 with children (7-10 years) of the five Brazilian regions, performed by the survey technique. In Brazil, leisure is a children's social right, which fortifies the international perspective of human rights. Brazilian children point out the school as their major obligation, followed by household duties. As for what they do as leisure, the physical-sporting interests are frequent activities over the weekend. In the weekdays, we did not have sufficient data to analyses the relationship between childhood and internet media. As for the barriers to living leisure, the lack of financial resource and time were revealed as great obstacles.

\section{KEYWORDS}

Child. Leisure activities. Human Rights.

\section{RESUMEN}

Presentamos análisis de lo que los niños hacen como ocio, lo que les gustaría hacer como ocio, lo que hacen como obligación, así como los obstáculos a las experiencias de ocio. El estudio presenta un nivel de confianza del 95\%, con muestreo total de 2400 entrevistas, siendo 211 con niños (7-10 años) de las cinco regiones brasileñas. El ocio se presenta como un derecho social para los niños, fortaleciendo la perspectiva de los derechos humanos. Los niños brasileños como obligación presentan la escuela como una respuesta frecuente, seguida de las tareas del hogar. En cuanto a lo que hacen como ocio, los intereses físico-deportivos son frecuentes durante el fin de semana, y durante la semana presentamos la necesidad de más datos sobre la infancia y los medios de Internet. En cuanto a las barreras para el ocio, la falta de recursos financieros y el tiempo se señalaron como los obstáculos.

\section{PALABRAS CLAVE}

Niños. Actividades recreativas. Derechos Humanos. 


\section{INTRODUÇ̃̃̃O}

A infância e o lazer são temas deste artigo que mostra como as crianças brasileiras têm vivenciado o lazer e como desejariam se apropriar dessa dimensão cultural. A sociedade moderna tem a infância como lugar privilegiado da brincadeira e do jogo, e, por isso, poucos debates têm sido realizados sobre o lazer e a infância. Nesse texto apresentamos como as crianças ocupam seu tempo e quais barreiras existem para vivenciar o lazer.

A história da criança brasileira acontece no quadro das mudanças societárias e, no Brasil, a legislação sobre direitos das crianças ocorre depois do reconhecimento internacional, reafirmado na década de 1990 pela criação do Estatuto da Criança e Adolescente. 0 país reconhece a criança como cidadã, detentora de direitos constitucionais, um ser participativo, atribuindo importância ao que pensam, sentem e desejam.

Toda criança, como sujeito de direitos, é representante legítima da cultura, de modos particulares de ser criança e expressão de diferentes infâncias. E, diferente do que se poderia pensar décadas passadas, as crianças realizam escutas e leituras do mundo, a partir das quais pensam sobre si, seu corpo, suas relações sociais, suas condições de vida. Além disso, as crianças são produtoras e produzidas pela cultura, o que exige desenvolvermos a possibilidade de lidar com o inacabado, “[...] com processos de significação, apropriação e ressignificação que constituem os modos particulares de conhecer e fazer das crianças e suas relações com os modos de fazer dos adultos no mundo” (SILVA, 2012, p. 41).

Esses marcos legais nos levam a crer, portanto, que o lazer estaria garantido às crianças e que caberia ao Estado estabelecer políticas públicas a fim de concretizar tal direito. Entendemos o lazer como um direito humano indivisível para as crianças, assim, esse artigo tem por finalidade identificar o lazer e as obrigações das crianças de 7 a 10 anos no Brasil.

\section{METODOLOGIA}

No contexto do lazer e com o objetivo de verificar como o brasileiro vivencia esse direito, o Ministério do Esporte (2003 - 2019) financiou uma pesquisa para conhecer o lazer do brasileiro, buscando compreender três questões: o que o brasileiro faz como lazer? O que gostaria de fazer, mas não faz como vivência de lazer? E por que não o faz? A pesquisa foi realizada com sujeitos de todo território brasileiro, contemplando os 26 estados e o Distrito Federal, com público-alvo formado pela população acima de 7 anos de idade.

O estudo apresenta um erro amostral máximo de $2 \%$ para o país e nível de confiança de $95 \%$, sendo o tamanho da amostra de 2400 entrevistas divididas nas cinco regiões brasileiras. Todos os procedimentos éticos foram seguidos, sendo o projeto aprovado pelo Comitê de Ética e Pesquisa $(\mathrm{COEP})^{6}$ da Universidade Federal de Minas Gerais. A pesquisa seguiu os princípios do Código Internacional de Conduta da Câmara Internacional de Comércio/Sociedade Europeia para a Pesquisa de Opinião e Mercado (ICC/ ESOMAR), documento que orienta a prática de pesquisa, aceito em âmbito internacional.

6 Parecer consubstanciado $n^{0} 284.603$, aprovado em 28/05/2013, pelo COEP/UFMG. 
Trata-se de pesquisa de caráter qualitativo e quantitativo, realizada pela técnica de survey, por levantamento amostral, com a coleta executada por meio de entrevistas pessoais, face a face, em pontos considerados de grande fluxo nas cidades sorteadas. 0 instrumento utilizado foi um formulário de entrevistas estruturado, composto de perguntas abertas e fechadas, sendo aplicado a uma amostra representativa da população brasileira, considerando, em cada estado, cotas de sexo, idade, escolaridade e renda familiar, de acordo com os dados da população apurados no Censo Demográfico 2010 do Instituto Brasileiro de Geografia e Estatística (IBGE).

As entrevistas foram checadas e inseridas em um banco de dados desenvolvido exclusivamente para esta pesquisa. Esse banco possui dados de validação que impedem a entrada de dados estranhos às respostas fechadas. Além disso, foi realizado teste de consistência em $100 \%$ dos dados.

O banco de dados seguiu as categorias dos interesses culturais do lazer estudadas na pesquisa de Dumazedier (1980), sendo físicos, intelectuais, manuais, artísticos, sociais e turísticos. Aos interesses físicos tratamos as vivências de lazer do movimento corporal humano como esporte, capoeira, danças, caminhadas, ginásticas etc. Os intelectuais são as vivências culturais marcadas pelo interesse em conhecimentos sistematizados como palestras, jogos de desafios como xadrez, dama etc. Os interesses manuais ou práticos se referem as vivências de produção de artesanatos, culinárias, jardinagem etc. Os interesses artísticos caracterizam as vivências de ir ao cinema, museu, espetáculos de dança ou exposições artísticas. Os sociais são vivências da cultura do encontro com outras pessoas, como ir a festas, bares etc. Por último, a categoria de interesses turísticos classificada por Camargos (1986), para demonstrar um grupo de interesses ligados a viagens e passeios.

Este artigo se propõe a trabalhar com um recorte caracterizado pela população de 7 a 10 anos de idade, composto por 211 crianças entrevistadas no Brasil. É importante ressaltar que o formulário estruturado apresentou mais de uma alternativa para as respostas, possibilitando mais de uma opção para cada questão. Dessa forma, alguns dados levantados ultrapassam o número de 211 respostas.

As questões norteadoras deste texto dizem respeito a: a) o que a população de 7 a 10 anos faz como obrigação? b) o que faz como lazer? c) o que gostaria de fazer? Os dados foram apresentados em gráficos e os conteúdos analisados, promovendo uma contextualização teórica a partir das respostas com maior incidência.

\section{A EDUCAÇ̃̃O COMO DIREITO DE MÃO DUPLA: ENTRE O DEVER E A OBRIGAÇ̃̃O}

Questionadas sobre suas atividades de obrigações, as respostas espontâneas das crianças - 7 a 10 anos de idade - são compreendidos neste estudo como: trabalho (1,4 \%); estudos e cursos $(94,4 \%)$; famílias e filhos (4,3\%); afazeres domésticos (28,2\%); compromissos religiosos (2,7\%); compromissos sociais/políticos ( $0,4 \%)$; outros (6,1\%). A análise realizada demonstra um envolvimento maior das crianças com estudos e cursos na infância e nos afazeres domésticos. 
Tabela 1 - 0 que as crianças fazem como obrigação no Brasil (espontânea)

\begin{tabular}{|c|c|c|}
\hline Frequência & Porcentagem & O que faz como obrigação (espontânea) \\
\hline 3 & $1.4 \%$ & Trabalho \\
\hline 193 & $94.4 \%$ & Estudo/cursos \\
\hline 9 & $4.3 \%$ & Família, filhos \\
\hline 58 & $28.2 \%$ & Afazeres domésticos \\
\hline 6 & $2.7 \%$ & Compromissos religiosos \\
\hline 1 & $0.4 \%$ & Compromissos políticos/sociais \\
\hline 13 & $6.1 \%$ & Outros \\
\hline
\end{tabular}

Fonte: Dados da pesquisa.

As temporalidades ajudam a entender o que as crianças consideram obrigação. Quando questionadas, $94,4 \%$ das crianças nomeiam os tempos de escola e cursos como tempos de obrigação. Tomando a escola como instituição promotora da educação e a educação como direito das crianças e dever dos responsáveis, a percepção das crianças sobre a escola como obrigação é distante da ideia de conquista desse direito social.

0 processo de democratização de acesso à educação em nível escolar, também nomeada de educação básica, no Brasil foi diversificado em seu território e contou como dispositivo a noção de obrigatoriedade para efetivação do direito. Segundo o Censo Escolar da Educação Básica 20177, do Ministério da Educação, foram realizadas 12.076.354 matrículas no ensino fundamental anos iniciais e 9.915.294 nos anos finais em escolas urbanas e rurais do país. Esse número se refere aos dados repassados pelos dirigentes escolares, públicos e privados, em relação às matrículas registradas no país.

Por outro lado, o último Censo demográfico de 2010 (IBGE, 2010), aponta que 966.305 crianças de 6 a 14 anos de idade estavam fora da escola. A taxa de escolarização líquida do ensino fundamental é de 96,5\% em 2015, o que significa que maior parte da população de 6 a 14 anos está escolarizada.

A História da Educação brasileira mostra que o tempo de escolarização obrigatória no Brasil aumentou nos últimos dez anos. A Emenda Constitucional 59 de 2009 (BRASIL, 2009) orienta a ampliação da Educação Básica no Brasil para crianças e jovens dos quatro aos dezessete anos de idade. Assim, os governos em todas as instâncias vêm promovendo políticas educacionais para ampliação de vagas nas unidades escolares para garantir ensino gratuito durante 14 anos da infância, diferentemente dos anos 1960 no Brasil, quando o ensino gratuito era apenas de quatro anos, o chamado curso primário.

Os avanços das legislações educacionais mostram um percurso de lutas de movimentos sociais para ampliação do direito à educação. Ao Estado não existe a opção de manter ou não as escolas e aos responsáveis das crianças não existe escolha sobre a permanência das crianças nas instituições escolares. Essa obrigação ultrapassa o direito individual das pessoas de ignorar o universo

7 Dado publicado pelo Gabinete do Ministro no Diário Oficial da União por meio da Portaria n. 1.069, de 6 de setembro de 2017. 
escolar. A educação é um fenômeno de "mão dupla” que possui em si o direito e a obrigação articulada no seu exercício ${ }^{8}$.

O trabalho doméstico é, também, obrigação para $28.2 \%$ das crianças respondentes. Embora a pesquisa apresente o termo "trabalho doméstico", a fala das crianças caminha no sentido do que Sabóia (2000) nomeia de "afazeres domésticos”.

Entende-se por pessoas ocupadas com afazeres domésticos, aquelas que, independentemente de estarem ocupadas ou não, costumam cuidar integralmente ou parcialmente dos afazeres domésticos no seu domicílio de residência de tarefas não econômicas (ou seja, que não atendam às condições estabelecidas no conceito de trabalho) como, por exemplo: a) Arrumar toda ou parte da moradia; b) Cozinhar ou preparar alimentos, lavar roupa ou louça, passar roupa, utilizando, ou não, aparelhos eletrodomésticos para executar estas tarefas para si própria ou para outro morador; dirigir empregados domésticos na execução das tarefas domésticas; ou d) Cuidar de filhos ou menores moradores. (SABÓIA, 2000, p. 4).

Sabóia (2000) afirma que historicamente no Brasil os afazeres domésticos são destinados as meninas e que é comum as crianças realizarem trabalho doméstico para sua família. "Em todo o mundo, a maioria das famílias espera que seus filhos ajudem nas tarefas domésticas, podendo ser benéfico este tipo de trabalho" (SABÓIA, 2000, p. 5). Essas tarefas de casa garantem a participação das crianças na família, contudo, essas ações nem sempre são equilibradas. A autora indica que "o trabalho para a família pode exigir muito da criança obrigando-a a trabalhar muitas horas e impedindo-a de frequentar a escola dificultando o exercício pleno de seus direitos” (SABÓIA, 2000, p. 5).

As tarefas domésticas podem dificultar a permanência de crianças no meio escolar, especialmente meninas que dedicam muitas horas a essas tarefas. Tal fato pode justificar a incidência dessa afirmação entre meninas e meninos. Quando questionados o que fazem por obrigação, $54.2 \%$ dos meninos pesquisados indicam estudos e cursos, enquanto esse número cai para $40 \%$ das meninas. E, opostamente, $11,1 \%$ dos meninos respondentes citam afazeres domésticos como uma obrigação, contra $16 \%$ das meninas.

\section{LAZER DAS CRIANÇAS BRASILEIRAS}

O lazer, como dimensão da cultura construída socialmente, em nosso contexto, se relaciona a partir de quatro elementos: o espaço lugar, as manifestações culturais, as ações ou atitudes fundamentadas no lúdico e o tempo. Esse tempo de usufruto do momento presente que não se limita aos períodos de férias e fins de semana (GOMES, 2004). Marcellino (2006) fala de tempo disponível para a

8 Vale ressaltar que, apesar de controversa, a proposta de implantação do homeschooling, modalidade de ensino que permite que as famílias promovam a formação acadêmica de suas crianças, tem sido pautada pela atual gestão do Governo Federal, que promete implementá-la por meio de medida provisória ainda em 2019. Em 2018, o Supremo Tribunal Federal (STF) decidiu não reconhecer essa modalidade de ensino. Para a Corte, a Constituição prevê apenas o modelo de ensino público ou privado, cuja matrícula é obrigatória, e não há lei que autorize a medida. 
vivência do lazer e, por isso, identificar o que as crianças fazem como lazer no fim de semana, durante a semana e nas férias mostra que grupos de conteúdos elas atribuem a categoria lazer. A pesquisa também apresenta que práticas estão disponíveis para as crianças brasileiras e com que frequência é possível vivenciá-las.

Tabela 2 - 0 que as crianças brasileiras fazem como lazer no fim de semana

\begin{tabular}{|c|c|c|}
\hline Frequência & Porcentagem & O que faz no fim de semana \\
\hline 1 & $0.4 \%$ & Ócio \\
\hline 47 & $22.9 \%$ & Turístico \\
\hline 269 & $131.5 \%$ & Físico-esportivo \\
\hline 20 & $9.5 \%$ & Artístico \\
\hline 77 & $37.4 \%$ & Social \\
\hline 2 & $0.9 \%$ & Intelectual \\
\hline 100 & $48.6 \%$ & Outros \\
\hline 1 & $0.4 \%$ & Qualificação, Estudo e/ou Cursos \\
\hline
\end{tabular}

Fonte: Dados da pesquisa.

No fim de semana as crianças afirmam que o interesse físico esportivo é o frequente $131,50 \%$. A popularização dos esportes no Brasil e a permanência desse conteúdo nos currículos escolares são um dos fatores que explicam a escolha por esse conteúdo do lazer. Com base no Diagnóstico Nacional do Esporte (DIESPORTE), pesquisa realizada no ano de 2015 com objetivo de mapear como se pratica esporte no Brasil, $48 \%$ das pessoas entrevistadas afirmaram ter iniciado a prática esportiva na escola, frequentada por esta faixa etária (BRASIL, 2015).

No final de semana a categoria "Outros" representa 48,06\% das respostas seguida de $37,40 \%$ dos interesses sociais. Os interesses turísticos aparecem com 22,90\% dos interesses das crianças. Já os artísticos representam $9,50 \%$ dos interesses das crianças brasileiras. Ócio e qualificação/estudos representam $0.4 \%$ das respostas cada.

Durante a semana das crianças existem alterações nas respostas. A semana é composta pelos tempos com obrigações infantis que se mesclam com os tempos que as crianças têm como disponíveis. Na Tabela 3 os interesses físico-esportivos são 77,20\% das respostas das crianças, indicando que os esportes são práticas inseridas na cultura das crianças brasileiras. De 2003 até 2019 houve uma ampliação de programas sociais de esporte e lazer no âmbito federal, e programas como o PST (programa Segundo Tempo) foram articulados nas escolas públicas de todo país. Os tempos escolares foram articulados a aulas esportivas e as crianças permaneciam nas escolas com atividades de lazer. O lazer das crianças brasileiras é influenciado pela cultura esportiva. 
Tabela 3 - O que as crianças fazem no tempo livre durante a semana

\begin{tabular}{|c|c|c|}
\hline Frequência & Porcentagem & O que faz durante a semana \\
\hline 2 & $0.9 \%$ & Ócio \\
\hline 8 & $3.7 \%$ & Turístico \\
\hline 158 & $77.2 \%$ & Físico-esportivo \\
\hline 8 & $3.7 \%$ & Artístico \\
\hline 20 & $9.5 \%$ & Social \\
\hline 3 & $1.3 \%$ & Manual \\
\hline 9 & $4.2 \%$ & Intelectual \\
\hline 179 & $87.5 \%$ & Outros \\
\hline 19 & $9.1 \%$ & Qualificação, Estudo e/ou Cursos \\
\hline
\end{tabular}

Fonte: Dados da pesquisa.

A categoria outros (87.5\%) assume protagonismo em práticas de lazer durante a semana, essas são as atividades que não se adequaram aos conteúdos organizados para as categorias prévias de lazer. Nos relatos das crianças compõem esse grupo: assistir jogo de futebol; assistir TV; computador; ficar no facebook; lan house; mexer na programação do PC; mexer no celular; navegar na internet; ver desenho; ver novela; fazer ligação e ficar no telefone. As diferentes mídias eletrônicas têm se articulado ao perfil da criança e adolescente no Brasil. A categoria 'outros' associada a outras pesquisas (COMITÊ..., 2017) mostra um novo perfil de viver o lazer.

A pesquisa TIC kids online Brasil do Comitê Gestor da Internet no Brasil (2017) informa que, embora ainda exista no Brasil 5,9 milhões ${ }^{9}$ de pessoas de 9 a 17 anos desconectadas da rede de internet, 24,7 milhões de crianças e jovens já usaram a rede. $93 \%$ desses acessos se dão por telefone celular, $53 \%$ por computadores e tablets, $25 \%$ pela TV e $16 \%$ por videogames. Esses dados apontam para formatos virtuais de viver o lazer em algumas infâncias e adolescências.

Silva, Tolocka e Marcellino (2006) apresentam, naquele ano, um conjunto de pesquisas, mostrando que ver TV era a principal atividade de lazer na infância, por fatores que trataremos no próximo tópico. Os autores mostram, também, que o número de crianças brasileiras que acessava o computador era de 13,44\%, embora ainda existam crianças que não acessem smartfones, tablets, computadores e Smarttvs, o acesso a esses eletrônicos produziu novas formas de lazer na infância, mediadas pelas tecnologias. Vale ressaltar os debates do mundo adulto sobre esses acessos que podem ser contrários aos usos de telas.

Nos tempos do fim de semana as atividades físico-esportivas ( $131.5 \%)$, outros ( $48.6 \%)$, os interesses sociais ( $37.4 \%)$ e os interesses turísticos (22.9\%) foram as atividades mais indicadas. Já durante a semana outros (87.5\%), físico-esportivos ( $77.2 \%)$, sociais (9.5\%) e os estudos e cursos (9.1\%) são como as atividades de lazer declaradas pelas crianças. Exceto pela prática do turismo e cursos, as práticas de lazer do final de semana e durante a semana não se distanciam indicando que em um curto espaço de tempo, as práticas de lazer das crianças são as mesmas.

9 Dessa população 3,4 milhões nunca acessaram a rede de internet no Brasil (COMITÊ..., 2017). 
Quando o tempo disponível tem outro formato mudam as possibilidades de viver o lazer. As férias escolares no Brasil se dão, frequentemente, em dois períodos, no fim do mês de julho até início do mês de agosto e no fim de dezembro até início de fevereiro. Tomando como referência o tempo disponível nas férias temos outros interesses culturais vivenciados.

Tabela 4 - o que as crianças brasileiras fazem como lazer durante as férias

\begin{tabular}{|c|c|c|}
\hline Frequência & Porcentagem & O que faz nas férias \\
\hline 97 & $47.5 \%$ & Ócio \\
\hline 48 & $23.5 \%$ & Turístico \\
\hline 26 & $12.7 \%$ & Físico-esportivo \\
\hline 6 & $2.9 \%$ & Social \\
\hline 2 & $0.9 \%$ & Outros \\
\hline 1 & $0.4 \%$ & Qualificação, Estudo e/ou Cursos \\
\hline 24 & $11.7 \%$ & Não sabe ou não respondeu \\
\hline Fonte: Dados da pesquisa. & &
\end{tabular}

A percepção sobre o ócio, inexpressiva nas tabelas 3 e 4 (0,4\% e 0,9\% respectivamente), ganha destaque na Tabela 4 durante as férias (47,5\%). Ficar em casa, dormir/descansar, ficar sozinho, não fazer nada e tomar sol são as respostas correspondentes à categoria ócio.

As atividades turísticas aparecem em segundo lugar (23,5\%) entre as atividades que as crianças realizam no período de férias, ela aparece também aos fins de semana com incidência de (22.9\%). A influência do nível social ${ }^{10}$ sobre o turismo também foi evidenciada nesta pesquisa. As crianças que vivem o ócio durante as férias se enquadram principalmente nas classes B2, C1 e C2 (sendo E a classe com menor poder de compra).

Essas classes têm como características o provedor familiar empregado e como consequência devem encontrar soluções para as férias infantis. Grande parte de crianças brasileiras precisam dos adultos responsáveis para acompanhá-las a diferentes espaços fora da casa. E quando esses adultos trabalham, essas crianças ficam em casa, ou em casas de parceiros que auxiliam com o cuidado (vizinhos, avós, creches). A situação social da criança, com frequência, acompanha o perfil social dos adultos responsáveis por ela.

As atividades turísticas aparecem em segundo lugar (23,5\%) entre as atividades que as crianças realizam no período de férias. As classes B1, B2, C1, C2 e D somam os $23 \%$ de crianças que vivenciam as atividades turísticas no período de férias. Evidenciam-se os diferentes tipos de viagens, de pacotes de viagens até as visitas às casas de parentes. Embora não tenhamos informações suficientes para

10 Para esta pesquisa, foi utilizado o Critério de classificação econômica Brasil, proposto pela Associação Brasileira de Empresas de Pesquisas (ABEP), vigente em 2013, que estima o poder de compra da população brasileira. Essa classificação faz a divisão do mercado em classes econômicas definidas como A1, A2, B1, B2, C1, C2, D e E, por meio da somatória de pontos relativos à posse de itens e grau de instrução do chefe de família (ABEP, 2008). 
afirmar que tipo de atividades turísticas as crianças referenciam, existe uma variedade de possibilidades dentro do conceito utilizado na pesquisa. Um fato é o tempo disponível do adulto que interfere nas atividades de lazer das crianças.

\section{AS BARREIRAS DO LAZER PARA A POPULAÇÃO DE 7 A 10 ANOS NO BRASIL}

Em uma sociedade marcada pelo valor do trabalho as práticas de lazer podem ser tomadas como desnecessárias. Existem fatores que impedem que o lazer aconteça e as Tabelas a seguir representam as barreiras de vivência do lazer no Brasil pelo olhar das crianças.

Tabela 5 - Barreiras que dificultam a vivência de lazer no tempo livre das crianças

\begin{tabular}{|c|c|c|}
\hline Frequência & Porcentagem & Porque não faz no tempo livre \\
\hline 40 & $19.5 \%$ & Tempo \\
\hline 32 & $15.6 \%$ & Espaço/local \\
\hline 2 & $0.9 \%$ & Saúde \\
\hline 46 & $22.5 \%$ & Dinheiro/recursos financeiros \\
\hline 66 & $32.2 \%$ & Outros \\
\hline 16 & $7.8 \%$ & Nada, faz tudo que gostaria \\
\hline 9 & $4.4 \%$ & Não sabe ou não respondeu \\
\hline
\end{tabular}

Fonte: Dados da pesquisa.

Tabela 6 - Barreiras que dificultam a vivência de lazer nas férias das crianças

\begin{tabular}{|c|c|c|}
\hline Frequência & Porcentagem & Porque não faz nas férias \\
\hline 33 & $16.1 \%$ & Tempo \\
\hline 6 & $2.9 \%$ & Espaço/local \\
\hline 1 & $0.4 \%$ & Saúde \\
\hline 113 & $55.3 \%$ & Dinheiro/recursos financeiros \\
\hline 37 & $18.1 \%$ & Outros \\
\hline 4 & $1.9 \%$ & Não sabe ou não respondeu \\
\hline
\end{tabular}

Fonte: Dados da pesquisa.

Quando questionadas sobre as férias (TABELA 6) 55,3\% das respostas indicam a falta de recurso financeiro e (TABELA 5) 22,5\% das respostas no tempo livre declaram falta de dinheiro. Essa é uma barreira comum em uma sociedade que transformou o lazer em mercadoria (MASCARENHAS, 2005) e a distribuição de renda é desigual. Desse modo, o acesso é garantido pela compra de um produto e o lazer é colocado em segundo lugar frente a prioridades das famílias (pagar aluguel, contas, médico, comida etc.). Autores como Mascarenhas (2005) indicam a ampliação no final do século XX e início do século XXI da mercadorização das práticas de lazer no Brasil e como a relação de mercado é mediada pelos recursos financeiros. 
No Brasil, 6 em cada 10 crianças e adolescentes são alocados nas categorias de pobreza. Em outras palavras, 18 milhões de crianças e adolescentes vivem em domicílios com renda per capta insuficiente para adquirir cesta básica. Essas condições afetam os direitos sociais cujos acessos sejam interpretados pela relação de mercado, como o lazer.

Quando se trata de outras barreiras (32,2\%, TABELA 5; 18,1\% TABELA 6) as respostas das crianças são variadas: porque precisa da permissão de alguém, ou de um adulto que acompanhe; porque é menor de idade; porque não fica quieto; porque os pais não gostam; porque os pais não viajam etc.

A categoria 'Outros' na pesquisa do lazer do brasileiro, referente às barreiras do lazer, indica que as crianças não acessam os bens culturais de nossa sociedade sozinhas. A ampliação dos ambientes urbanos bem como sua mercantilização, o aumento de transportes motorizados, a diminuição do tamanho das casas e o aumento de violência (SILVA; TOLOCK; MARCELINO, 2006) foram mudanças essenciais no lazer. As ruas, antigos territórios de brincadeiras e partilhas coletivas de jogos, são tomadas por veículos e as famílias confinadas em apartamentos ou casas. As crianças estão todo o tempo tutoreadas por alguma figura adulta (professor, cuidador, pais etc.). E as decisões das crianças são mediadas pelo adulto.

Os adultos apresentam expectativas sobre o futuro das crianças, tal qual nos lembra Sacristán (2005, p. 26), quando afirma que "aprendemos coletivamente a ser de uma forma determinada com os menores11, a cuidar, a disciplinar, a amar e a vê-los voltados para um futuro". A visão do adulto sobre o futuro da criança estabelece os padrões de importância nas vivências que ele possibilitará a ela. O futuro exige habilidades que devem ser acessadas na infância e a infância passa a ser um lugar de preparação para a vida adulta.

E nessa busca por preparar a criança para a vida adulta "bem-sucedida", a falta de tempo também se apresenta como uma barreira que afeta a população de 7 a 10 anos de idade no Brasil. 19.5\% (TABELA 5) das crianças dizem sobre a falta de tempo como barreiras nos tempos livres e 16.1\% (TABELA 6) como barreiras nas férias.

A socialização das crianças predestinadas ao sucesso, pela sua situação de classe, começa cada vez mais precocemente. 0 fundamental para essas crianças é que sejam ocupadas, o que significa administrar seu tempo. Essa e a recomendação desde os "jardins de infância" e das escolas "pré-primários". Para os excluídos do sistema escolar, ou para os que a ele tem acesso de modo fragmentado, recomenda-se a ocupação do tempo das crianças nas escolas, mas também fora delas. O presumido "tempo livre", por seu caráter ambíguo, é visto dentro de uma perspectiva moralista. (MARCELLINO, 1996, p. 82).

O Brasil busca ampliar o acesso das crianças a diferentes atividades nos contraturnos escolares, recorrentemente com objetivos de controlar as atividades que a criança acessa. As práticas de lazer promovidas pelos adultos para as crianças são expressão dos entendimentos de classe social, de mercado e de futuro posto socialmente.

11 Termo utilizado pelo autor para explicar que o menor é o ser humano que "não é adulto", para ele, o termo menor é mais amplo que criança. São sujeitos cuja voz não é importante. Os menores são projeções que os adultos fazem deles e sobre eles, quase nunca com eles. 
Outra barreira encontrada entre os respondentes são os espaços e locais para a vivência das atividades de lazer com 15,6\% (TABELA 6). Em uma pesquisa realizada em dois bairros de Belo Horizonte, Debortoli e outros autores (2008) chama a atenção para as particularidades dos diferentes espaços da cidade. Em um dos bairros, considerado um refúgio da elite econômica, as relações adulto/criança são marcadas pelo distanciamento. Segundo o autor, a lógica dos edifícios opulentos, com diversos equipamentos de lazer, deixa em segundo plano a reunião das pessoas (DEBORTOLI et al., 2008).

Sobre a apropriação do espaço público neste contexto abastado, o autor destaca a escassez de relações espontâneas, de atividades que não acontecem fora de espaços e horários predeterminados. Fazendo um contraponto, o outro bairro é constituído pela periferia da mesma cidade e tem suas ruas como único espaço público com possibilidade de encontro e trocas, mesmo que de forma e sentido nostálgicos (DEBORTOLI et al., 2008). Essa pesquisa revela quão diversas e complexas são as experiências de infância nos contextos urbanos.

\section{CONCLUSÕES}

Identificamos, no que se refere a garantida dos direitos das crianças, que o movimento brasileiro acompanha a movimentação internacional e, a partir de 1990, as crianças são discutidas na agenda política e nas pautas sociais. O Brasil integrou-se à Convenção Internacional sobre os Direitos da Criança, ratificada pelo Congresso Nacional, temos o Estatuto da Criança e do Adolescente (ECA).

No que diz respeito à consolidação do lazer para crianças de 7 a 10 anos no Brasil, a pesquisa aponta que, como obrigação, a escola é a resposta de $94,4 \%$ das crianças, seguida pelos afazeres domésticos respondidas por $16 \%$ das meninas e $11,1 \%$ dos meninos respondentes. Pelas respostas das crianças e adolescentes, os interesses físico-esportivos são as práticas mais vivenciadas no fim de semana ( $131,5 \%$ das respostas) e a segunda atividade mais praticada durante a semana $(77,2 \%)$. As atividades sociais compõem $37,4 \%$ das atividades no fim de semana e $9,5 \%$ durante a semana. No que se refere aos lazeres durante a semana, esta pesquisa apresenta a necessidade de dados que dialoguem com a infância e as mídias de acesso as redes de internet.

A percepção sobre o ócio durante as férias atinge 47,5\% das crianças brasileiras. Ficar em casa, dormir/descansar, ficar sozinho, não fazer nada e tomar sol são as respostas correspondentes à categoria ócio. As atividades turísticas aparecem em segundo lugar (23,5\%) nas respostas das crianças e adolescentes como o que fazem nas férias. Os interesses físico-esportivos aparecem em 12,7\% dos respondentes o que se contrapõe em termos percentuais às escolhas feitas durante os finais de semana no período escolar.

As crianças indicam $55,3 \%$ à falta de recurso financeiro quando questionadas sobre as barreiras para viver o lazer, ou “por que não fazem nas férias?" E esse dado também é representado em 22,5\% das respostas na pergunta “por que não faz nos tempos livres?” Além disso, 19.5\% das crianças dizem sobre a falta de tempo como barreiras nos tempos livres e $16.1 \%$ como barreiras nas férias. Outra barreira encontrada entre os respondentes foram os espaços e locais para a vivência das atividades de lazer com 15,6\%. 
Nesse sentido, as barreiras do lazer apontadas nesta pesquisa indicam a necessidade de aprofundamento na relação criança, adultos e os tempos/espaços da cidade. Tais barreiras apontam a necessidade de mais políticas públicas, privadas e do terceiro setor na área do lazer, em suas diferentes inter-relações com as demais políticas sociais, que tenham preocupação com a questão da criança uma vez que tais barreiras são elementos injustos para a apropriação de um direito que é de todos.

\section{REFERÊNCIAS}

BRASIL. Emenda Constitucional n0 59, de 11 de novembro de 2009. Disponível em: http://www. planalto.gov.br/ccivil_03/constituicao/emendas/emc/emc59.htm. Acesso em: 18 maio 2019.

BRASIL. Diagnóstico Nacional do Esporte. Brasília: Ministério do Esporte, 2015. Disponível em: http://www.esporte.gov.br/diesporte/diesporte_grafica.pdf. Acesso em: dez. 2018.

CAMARGO, Luís Otávio de Lima. 0 que é o lazer. São Paulo: Brasiliense, 1986.

COMITÊ Gestor da Internet no Brasil. TIC kids online Brasil 2017. Pesquisa sobre o uso da internet por crianças e adolescentes no Brasil: Núcleo de Informação e Coordenação do Ponto BR (ed.). São Paulo: Comitê Gestor da Internet no Brasil, 2018.

DEBORTOLI, José Alfredo Oliveira et al. As experiências de infância na metrópole. In: DEBORTOLI, José Alfredo Oliveira; MARTINS, Maria de Fátima Almeida; MARTINS, Sérgio (org.). Infâncias na Metrópole. Belo Horizonte: Editora UFMG, 2008.

DUMZEDIER, Joffre. Valores e conteúdos culturais do lazer. São Paulo: SESC, 1980.

GOMES, Chrisrianne Luce (org.) Dicionário crítico do lazer. Belo Horizonte: Autêntica Editora, 2004.

IBGE - Instituto Brasileiro de Geografia e Estatística. Síntese de Indicadores Sociais 2010. Rio de Janeiro: IBGE, 2010.

MARCELLINO, Nelson Carvalho. Elementos para o entendimento do uso do tempo na infância, nas suas relações com o lazer. Motrivivência, n. 9, p. 78-88, 1996.

MARCELLINO, Nelson Carvalho. Estudos do lazer: uma introdução. 4. ed. Campinas, SP: Autores Associados, 2006.

MASCARENHAS, Fernando. Entre o ócio e o negócio: teses acerca da anatomia do lazer. Tese (Doutorado) Faculdade de Educação Física, Universidade Estadual de Campinas. Campinas, SP, 2005. 
SACRISTÁN, José Gimeno. 0 aluno como invenção. Tradução: Daisy V. de Moraes. Porto Alegre, 2005.

SILVA, Junior Vagner Pereira. O lazer de interesse físico-esportivo no cotidiano infantil e sua interface com a saúde. Licere, Belo Horizonte, v. 15, n. 1, mar. 2012.

SILVA, Junior Vagner Pereira; TOLOCKA, Rute Estanislava; MARCELLINO, Nelson Carvalho. Lazer infantil-Direitos legais, transformações sociais e implicações ao crescimento e habilidades motoras básicas. LICERE - Revista do Programa de Pós-graduação Interdisciplinar em Estudos do Lazer, v. 9, n. 1, 2006.

SABÓIA, Ana Lúcia. As meninas empregadas domésticas: uma caracterização socioeconômica. Série Estratégias para Combater o Trabalho Infantil no Serviço Doméstico. Rio de Janeiro: OIT/ IPEA, 2000. Disponível em: http://ilo-mirror.library.cornell.edu/public/english/standards/ipec/ publ/policy/papers/brasil/oitana.pdf. Acesso em: 31 out. 2019.

UNICEF - Fundo das Nações Unidas para a Infância. Pobreza na infância e na adolescência. Brasil, 2018. Disponível em: https://www.unicef.org/brazil/relatorios/pobreza-na-infancia-e-na-adolescencia. Acesso em: dez. 2018. 
1 Doutora em Estudos do Lazer - UFMG; Professora do Departamento de Ciências do Movimento Humano - UEMG/ Ibirité; Coordenadora do curso de Ed. Física UEMG/lbirité; Colíder do Ciranda - Laboratório de Lazer, Infância e Cidade; Integrante dos grupos de pesquisa Oricolé e GESPEL; Pesquisadora associada ANPEL e CBCE; Formadora do Programa esporte e Lazer da Cidade e Vida Saudável PELC/VS/UFMG (2013-2019); Tesoureira do Sindicato docente - UEMG/ ADUEMG.

E-mail:sheylazarth.ribeiro@uemg.br

2 Doutora em Estudos do Lazer - UFMG; Professora da Universidade Salgado de Oliveira - UNIVERSO/Unidade Belo Horizonte; Diretora de Lazer da Secretaria Municipal de Esporte e Lazer de Nova Lima; Integrante do Ciranda - Laboratório de Lazer, Infância e Cidade e dos grupos de pesquisa Oricolé e GESPEL.

E-mail: aladiamedina34@gmail.com

3 Mestre em Estudos do Lazer - UFMG; Professor do Departamento de Ciências do Movimento Humano UEMG/lbirité; Líder do Ciranda - Laboratório de Lazer, Infância e Cidade. E-mail:Luciano.coelho@uemg.br

4 Doutor em Educação Física - UNICAMP; Pós-Doutor em Educação - UFRJ; Professor do Programa de PósGraduação Interdisciplinar em Estudos do Lazer - UFMG/ Brasil; Líder do Oricolé - Laboratório de Pesquisa sobre Formação e Atuação profissional em Lazer - UFMG. E-mail: helderisayama@yahoo.com.br

5 Doutor em Educação Física - UNICAMP; Professor do Programa de Pós-Graduação em Turismo da Escola de Artes, Ciências e Humanidades - USP; Colíder do Grupo Interdisciplinar de Estudos do Lazer - GIEL/USP. E-mail:stoppa@usp.br
Recebido em: 31 de Julho de 2020

Avaliado em: 4 de Março de 2021

Aceito em: 8 de Março de 2021

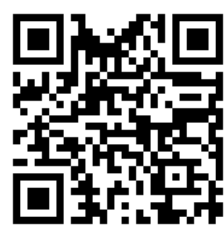

A autenticidade desse artigo pode ser conferida no site https://periodicos. set.edu.br

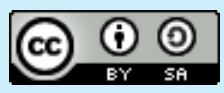

Este artigo é licenciado na modalidade acesso abertosob a Atribuição-Compartilhalgual CC BY-SA 